\title{
Possibilities of Additive Technologies for the Manufacturing of Tooling from Corrosion-Resistant Steels in Order to Protect Parts Surfaces from Thermochemical Treatment
}

\author{
Alexander Metel ${ }^{1}\left(\mathbb{D}\right.$, Tatiana Tarasova ${ }^{1}$ (D), Evgenii Gutsaliuk ${ }^{1}$, Roman Khmyrov ${ }^{1}$, Sergei Egorov ${ }^{1,2, *}$ \\ and Sergey Grigoriev ${ }^{1}$ (D) \\ 1 Department of High-Efficiency Machining Technologies, Moscow State University of Technology «STANKIN», \\ 127055 Moscow, Russia; a.metel@stankin.ru (A.M.); tarasova952@mail.ru (T.T.); \\ e.gutsalyuk@rambler.ru (E.G.); r.khmyrov@stankin.ru (R.K.); s.grigoriev@stankin.ru (S.G.) \\ 2 Swiss Federal Institute of Technology (ETH Zurich), 8092 Zurich, Switzerland \\ * Correspondence: egorov@iwf.mavt.ethz.ch
}

check for

updates

Citation: Metel, A.; Tarasova, T.; Gutsaliuk, E.; Khmyrov, R.; Egorov, S.; Grigoriev, S. Possibilities of Additive Technologies for the Manufacturing of Tooling from Corrosion-Resistant Steels in Order to Protect Parts Surfaces from Thermochemical Treatment. Metals 2021, 11, 1551. https://doi.org/10.3390/met11101551

Academic Editor: Youngsik Kim

Received: 31 August 2021

Accepted: 24 September 2021

Published: 29 September 2021

Publisher's Note: MDPI stays neutral with regard to jurisdictional claims in published maps and institutional affiliations.

Copyright: (c) 2021 by the authors. Licensee MDPI, Basel, Switzerland. This article is an open access article distributed under the terms and conditions of the Creative Commons Attribution (CC BY) license (https:/ / creativecommons.org/licenses/by/ $4.0 /)$.

\begin{abstract}
The structure and physical-mechanical properties of products made from powders of corrosion-resistant steel 12X18H10T by the laser-beam powder bed fusion (LB-PBF) and subsequent ion-plasma nitriding in the work were investigated. Comparative studies of the physical mechanical properties of specimens made by the LB-PBF and conventional method from steel of the same grade were carried out. The density of the specimens and the coefficient of linear thermal expansion (CLTE) after the LB-PBF are almost the same as those of the conventionally manufactured specimens. Our analysis of the obtained dilatograms in the temperature range from 20 to $600{ }^{\circ} \mathrm{C}$ showed that the CLTE of steel after the LB-PBF is within acceptable limits $\left(18.6 \times 10^{-6} 1 /{ }^{\circ} \mathrm{C}\right)$. Their hardness, tensile strength, yield strength and elongation are higher than those of a conventionally manufactured specimen. The phase composition and structure of specimens of steel 12X18H10T made by the LB-PBF after the process of ion-plasma nitriding were investigated. The obtained results show that the mode of ion-plasma nitriding used in this case (stage $1-570^{\circ} \mathrm{C}$ for $36 \mathrm{~h}$; stage $2-540{ }^{\circ} \mathrm{C}$ for $12 \mathrm{~h}$ ) does not lead to deterioration of the characteristics of the selected steel. A technological process for the manufacture of modified tooling from 12X18H10T steel by the LB-PBF was developed. It protects the surfaces that are not subject to nitriding and makes it possible to obtain a uniform high-quality nitrided layer on the working surface of the part made from spheroidal graphite iron.
\end{abstract}

Keywords: additive technologies; selective laser melting; ion-plasma nitriding; austenitic steel; spheroidal graphite iron; laser beam powder bed fusion

\section{Introduction}

Additive manufacturing is defined as the process of coupling materials to create objects from 3D model data, layer by layer. It is opposed to "subtractive" manufacturing methods, such as traditional machining [1].

Additive manufacturing (AM) makes it possible to create products of complex shapes that cannot be manufactured by conventional methods. AM makes it possible to reduce the time between the drawing and the final product, reduce the production time of the product, reduce material consumption and shorten the technological cycle by reducing the number of operations. Nowadays, one of the most promising areas of AM is the manufacturing of products from metal powders by the laser beam powder bed fusion (LB-PBF) and direct metal deposition (DMD) [2-5]. The range of materials used is expanding, along with the widespread use of corrosion-resistant steels; research is underway to determine the optimal parameters for the manufacture of products such as ceramics, metal alloys and composite materials [6-8].

The authors of Reference [9] investigated the microstructure and electrochemical behavior of 316L steel processed by LB-PBF in a concentrated solution $(0.9 \mathrm{M} \mathrm{NaOH}+0.9 \%$ 
$\mathrm{NaCl}$ ). It has been shown that the LB-PBF method does not reduce the corrosion resistance of 316L steel in an alkaline solution and in some cases shows better electrochemical characteristics in comparison with a wrought alloy. In addition, the alloy treated with LB-PBF showed a lower defect density compared to the wrought alloy.

The authors of Reference [10] analyzed the influence of SLM processing parameters, such as scanning strategy, powder layer thickness, laser power, scanning speed, on surface morphology and surface texturing, which ultimately determine the mechanical properties and functionality of the final product.

The authors of References [11,12] showed the possibility of temperature control in the process of the LB-PBF and DMD. An original optical diagnostic system was developed. The aim of the study was to improve product quality and ensure the stability and reproducibility of the process, using optical monitoring. The works used Ti6Al4V powder, two originally developed pyrometers and a FLIR Phoenix RDAS TM infrared camera. Changes in the pyrometer signal and brightness temperature from the operating parameters of the processes were analyzed. The possibility of manufacturing parts of almost any complexity is shown.

In Reference [13], the authors noted that one of the most promising methods of additive manufacturing is LB-PBF. However, this method has very low productivity, thus limiting its widespread use. The solution of this problem will make it possible to obtain metal 3D objects of complex geometry in a short time. The authors propose to improve the method by installing laser-beam profiling systems and online monitoring on the developed experimental setup. Alternative distributions of the power density of the laser beam are obtained. Online video surveillance has shown that, with the use of a laser beam profiling system, the negative effects of the process are noticeably reduced.

The use of corrosion-resistant steel powders in AM is of great interest both for research and for applied needs [14-17]. The following grades of corrosion-resistant steels are widely used in the LB-PBF: austenitic corrosion-resistant steels (AISI 316L, Russian analogue03X17H14M3; AISI 304L, Russian analogue-03X18H11) and martensitic corrosion-resistant steels (AISI 420, Russian analogue-20X13, 30X13, 40X13) [10,13,15,17-20].

In Reference [17], the authors implemented a model for calculating thermal fields for various schemes of laser processing of corrosion-resistant steels, making it possible to obtain estimated geometric dimensions of melting zones during laser heat treatment and LB-PBF. It is shown that, during laser heat treatment of corrosion-resistant steels and LB-PBF of corrosion-resistant steels, a quenching mechanism from the liquid state is realized. In this case, the structure of the melting zones is determined by the cooling rate.

The authors of Reference [18] studied the possibilities of using the methods of scanning electron microscopy and particle size analysis for the study of domestically produced powders from corrosion-resistant steels of 12X18H9T (AISI 321) and 20H13 (AISI 420); the grades are considered for the purpose of their application in LB-PBF technology.

Corrosion-resistant steels are most actively used in the aerospace industry, for example, in the manufacture of aircraft exhaust pipes, technological equipment, cabin heaters, etc. [21]. The authors of References [22,23] showed the possibility of replacing conventional methods of manufacturing aircraft airframe parts from corrosion-resistant steels 20X13 and X18H9T (washers of the airframe lock mechanism and air intake gratings) with an alternative technology, i.e., laser-beam powder bed fusion.

At present, research is underway quite actively on the influence of various postprocessing methods on the properties of parts manufactured by additive technologies. The authors of Reference [22] conducted research on the effect of post-treatment (heat treatment, ultrasonic liquid treatment and vibration tumbling) on the mechanical characteristics and surface quality of parts made by the LB-PBF from corrosion-resistant steels $20 X 13$ and X18H9T. The effect of heat treatment on the hardness and wear resistance of $20 X 13$ steel specimens manufactured by the LB-PBF was determined. The values of wear resistance and hardness of specimens obtained by LB-PBF with and without low tempering differ insignificantly. Abovementioned values slightly higher than the wear resistance of 
specimens after conventional quenching and low tempering. Investigated the influence of ultrasonic treatment and vibration tumbling on the surface quality of parts. It has been established that the use of ultrasonic treatment and vibration tumbling after LB-PBF allows us to improve the surface quality by reducing the roughness at the micro level and submicro level. The influence of the post-processing parameters on the mechanical characteristics of products manufactured by the LB-PBF method is determined to ensure the required properties of aerospace parts made of corrosion-resistant steels by the selective laser melting method.

The authors of Reference [8] consider shot blasting to reduce stresses and structural defects as a post-processing of specimens made of corrosion-resistant 316L steel by laser cladding. It is shown that the surface stress of the specimen formed by the hybrid process changed from tensile to compressive stress. At the same time, internal microdefects such as pores were reduced. The porosity of the specimen formed by the hybrid process was reduced by $90.12 \%$ than that of the laser cladding specimen, and the surface roughness decreased by $43.16 \%$.

It is shown that in the process of the LB-PBF a finely dispersed structure is formed. That provides higher strength properties of steels after the LB-PBF than after conventional processing. The density of the specimens is at the similar level. The study of the effect of heat treatment on the mechanical characteristics of corrosion-resistant steels showed that the hardness of 20X13 steel specimens obtained by the LB-PBF is higher than that of a conventionally heat treated specimens. The wear resistance decreases with an increasing in the tempering temperature for all test specimens [22]. The authors of Reference [24] show that the grain size in specimens made using low power is smaller than in specimens made at higher power. The reason for it is that higher powers have a greater thermal effect on a larger melting pool. Specimens built by using lower power have a lower thermal gradient and slower cooling rate.

Despite the large number of different studies of corrosion-resistant steels obtained by the LB-PBF, a number of unsolved scientific and technological problems still remain. It affects the quality and cost of the products. Not enough attention is paid to the influence of thermal and thermochemical treatments on the products structure and properties. Research in this area is necessary to solve specific problems of using LB-PBF of corrosion-resistant steels in the engineering industry, particularly in the manufacture of various types of tooling. AM makes it possible to manufacture tooling for certain technological operations. For the manufacture of products that meet customer requirements, various types of tooling are used. The types of tooling are made for strictly defined operations. The use of additive technologies makes it possible to take into account the design features of the future tooling and design it strictly for a specific product. Currently, to increase the wear resistance of the parts, various types of thermal and thermochemical treatments are used; research is underway to develop new functional coatings with unique properties [25-27]. At the same time, there is a need to protect surfaces that are not subject to hardening. For this purpose, various methods are used, from special coatings to the manufacture of tooling. For example, it was used in the operations of ion-plasma nitriding. Specifically made equipment in the form of casings is used, and it covers certain surfaces from nitriding. The use of additive technologies makes it possible to manufacture special alloys tooling with specific complex shape. In this case, AM shows the maximum material utilization rate. Possibilities of using additive technologies for the manufacture of tooling from metal powders to protect the surfaces of parts from thermochemical treatment have received insufficient attention. It cannot be ruled out that the microstructure of products produced by the LB-PBF is exposed to saturating gases in a completely different way than the microstructure of products manufactured by conventional methods. There is a complex metal science task requiring a large number of experiments and studies on the effect of thermochemical treatment on the material made by AM. 
The purpose of this work is to study the structure and physicomechanical properties of products made from domestically produced corrosion-resistant steel 12X18H10T powders by the LB-PBF and subsequent ion-plasma nitriding.

\section{Materials and Methods}

Corrosion-resistant chromium-nickel austenitic steel, grade X18H9T, was chosen as a material for the study. Metal powders of steel X18H9T (PRX18H9T, fraction from 20 to $63 \mu \mathrm{m}$ ) were prepared by AO "POLEMA" (Tula, Russia) by dispersing a molten metal by a jet of compressed gas. The choice of materials was determined by the request of aviation industry enterprises. It was used for the development of technological processes for the manufacture of tooling using AM. The paper investigates the possibility of replacing the conventional manufacturing technology of protective tooling by the production of nitrided parts with the LB-PBF technology.

In the work, the block part made from spheroidal graphite iron was considered. The flat end of the block was subjected to nitriding, while a number of surfaces were protected from nitrogen saturation. For this purpose, according to the conventional technology, tooling is made from steel 12X18H10T (Figure 1a).

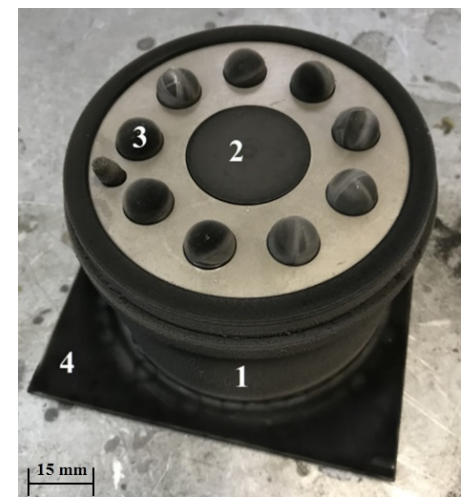

(a)

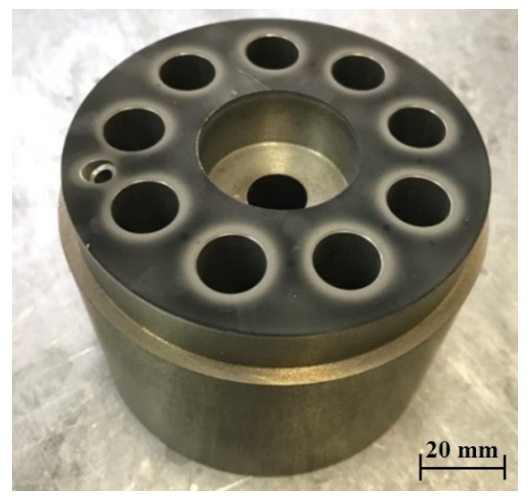

(b)

Figure 1. (a) Block blank in conventional tooling for ion-plasma nitriding; (b) block blank after ion-plasma nitriding (light gray zones with reduced hardness as a result of shielding from balls are clearly visible).

The production goal was to design a structure and develop a manufacturing process using the LB-PBF method for protective tooling. The tooling protects blocks made from spheroidal graphite iron used in piston pumps for aircraft engines from ion-plasma nitriding in order to improve the quality of the nitrided layer. The goal was achieved by the completion of studies of the physical and mechanical properties of specimens made from corrosion-resistant steel 12X18H10T by laser-beam powder bed fusion. The chemical composition of spheroidal graphite iron is shown in Table 1. Block blank is nitrided by using conventional tooling to protect surfaces that are not subject to nitriding.

Table 1. Chemical composition of spheroidal graphite iron MN.

\begin{tabular}{ccccccccc}
\hline Element & Fe & C & Si & Ni & Mn & Mg & S & P \\
\hline wt. $\%$ & Bal. & 3.21 & 2.86 & 0.87 & 1.02 & 0.05 & 0.017 & 0.08 \\
\hline
\end{tabular}

Tooling made in a conventional way does not provide a sufficient quality of the nitrided layer on the surface of the part (Figure 1b).

The block diameters are closed with a casing (1) and a cover (2), and the holes are closed with balls (3). The part stands on a sheet (4) with a $\varnothing 0.75 \mathrm{~mm}$ drilled hole for vacuum pumping. The casing, sheet and cover are made from steel 12X18H10T; the balls are made from steel IIIX15 (Figure 1a). 
After ion-plasma nitriding, at the holes closed with balls, zones with a reduced hardness are formed (Figure 1b). Such zones appear due to the shielding of the cast-iron surface by balls. To eliminate this problem and obtain a high-quality nitrided layer on the working surface of the block, it is proposed to modernize the design of the tooling and manufacture it by the LB-PBF. A 3D model of the upgraded tooling is shown in Figure 2.

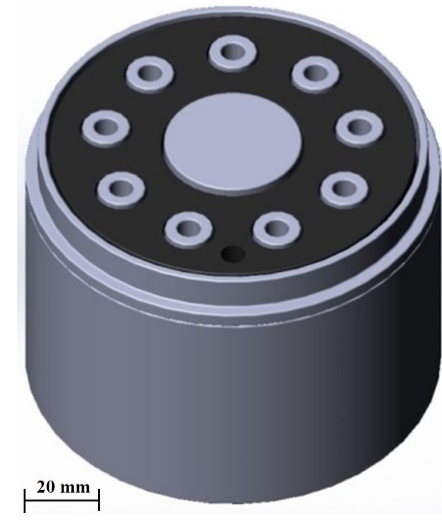

(a)

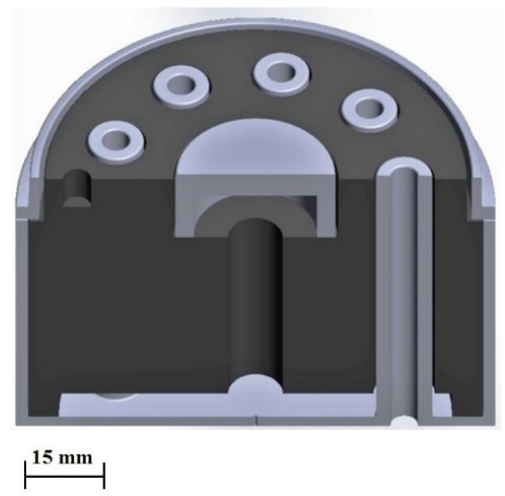

(b)

Figure 2. Three-dimensional model of the modernized equipment: (a) "new" tooling and sketch of the assembled block and (b) section of the 3D model.

The non-nitriding holes are closed from below, thereby eliminating the shielding effect during the ion-plasma nitriding process. The advantage of the new tooling is a high material utilization rate, as well as ease of use. The operational requirements for the tooling are as follows:

- The tooling geometry must provide a uniform nitriding layer on the block surface; the tooling components must cover the non-nitrided surfaces.

- The chemical composition and microstructure of the steel must ensure the depth of the nitrided layer is no more than $1 / 2$ of the wall thickness of the tooling for a long period of time (to increase the service life).

- The nitrided layer, regardless of the service life, should not become embrittled.

The material for the tooling is austenitic steel $12 \mathrm{X} 18 \mathrm{H} 10 \mathrm{~T}$, since this steel is almost not prone to nitriding.

Ion-plasma nitriding of blocks made from spheroidal graphite iron was carried out on an ELTROPULS H60/100 (ELTROPULS Anlagenbau GmbH, Baesweiler, Germany). Nitriding mode double-stage: 1 st stage $-570{ }^{\circ} \mathrm{C}, 36 \mathrm{~h}$; 2 nd stage $-540{ }^{\circ} \mathrm{C}, 12 \mathrm{~h}$. Before nitriding, cleaning is carried out in a hydrogen environment for $10 \mathrm{~min}$ at a temperature of 280 degrees and a pressure of $5 \mathrm{~Pa}$.

Laser-beam powder bed fusion was carried out on an EOS M 280 (EOS GmbH, Krailling, Germany).

The granulometric analysis of the powders was carried out on an OCCHIO500nano image analyzer manufactured by OCCHIO SA (Belgium) by static image analysis, according to ISO 13322-1: 2014 [4,21]. Real-time chemical analysis and particle morphology were determined on a VEGA 3 LMH scanning electron microscope (TESCAN, Brno, Czech Republic).

The microstructure and microrelief of the steels surface were studied, using an optical microscope Carl Zeiss AxioObserver D1m (Carl Zeiss, Oberkochen, Germany) and an electron microscope Phenom ProX (Thermo Fisher Scientific, Waltham, MA, USA), in accordance with GOST 5639-82 and GOST 1583-93.

X-ray phase analysis was carried out on an X-ray machine for structural analysis ARL X'TRA (Thermo Fisher Scientific, Waltham, MA, USA) by scanning with X-ray according to the Bregg-Brentano method. An X-ray tube with a copper $\left(\mathrm{CuK}_{\alpha}\right)$ anode was used to excite the characteristic spectrum. To record the diffraction pattern, a $\mathrm{Si}(\mathrm{Li})$ semiconductor 
detector was used, which suppresses the white radiation of the anode and the $\beta$-line of the $\mathrm{X}$-ray tube spectrum in a ratio not worse than $1 / 300$ with respect to $K \alpha$. The work of the machine is carried out by the WinXRD 2.0-8 control software and the ICDDPDF-2 reference radiographs database (2010). X-ray diffraction patterns were taken at a maximum goniometer radius of $520 \mathrm{~mm}$, a tube current of $30 \mathrm{~mA}$ and an accelerating voltage of $40 \mathrm{kV}$. The horizontal collimation slits (limiting the vertical divergence of the $\mathrm{X}$-ray beam) were $2 \mathrm{~mm} \times 2 \mathrm{~mm}$ in size. When taking X-ray diffraction patterns, a continuous method of counter movement with an angular velocity of $1.0^{\circ} / \mathrm{min}$ was used in the range of angles $\left(10^{\circ}-120^{\circ}\right)-2 \Theta$.

Measurements of the geometric parameters of the products were carried out on a multisensor coordinate measuring machine for high-precision measurements (WerthMesstechnik, Giessen, Germany); roughness measurements were performed on a profiler-profilometer (HommelTester T8000, Jena, Germany).

The density of the specimens was determined by hydrostatic weighing on a MettlerToledo XP504 balance with an accuracy of $0.001 \mathrm{~g} / \mathrm{cm}^{3}$.

Gas porosity was determined on panoramic images with an area of $4 \mathrm{~mm}^{2}$, using a Carl Zeiss AxioObserver D1m optical microscope. Image processing was performed by using the ThixometPro program. The volume fraction of pores, their size distribution and the total porosity score were evaluated.

Vickers microhardness was determined in accordance with GOST R ISO 6507-1-2007, using an Instron Wilson Hardness Group Tukon 2500 (Instron, Norwood, Massachusetts, USA) microhardness tester.

The INSTRON Electropuls E10000 testing system was used to measure tensile strength, yield strength and elongation.

The dilatometric analysis of LB-PBF-manufactured 12X18H10T steel specimens was carried out by using a LINSEIS L75H/1400 (LINSEIS, Selb, Germany) differential dilatometer. Dilatometric analysis was carried out in order to reveal changes in the Coefficient of Linear Thermal Expansion (CLTE) upon repeated heating from 20 to $600{ }^{\circ} \mathrm{C}$. That specified parameter must be taken into account when determining the dimensions of the tooling.

\section{Results and Discussion}

The results of the granulometric and granulomorphological analysis show that the powder of steel $12 \mathrm{X} 18 \mathrm{H} 10 \mathrm{~T}$ is characterized by a spherical particle shape with a small number of rod-shaped particles, high fluidity, microcrystalline structure, equiaxial morphology and a small number of satellites (Figure 3).

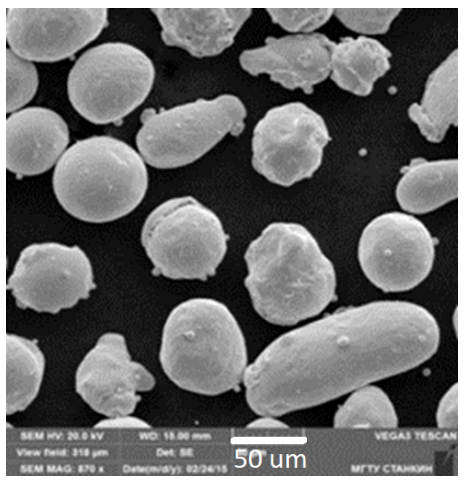

(a)

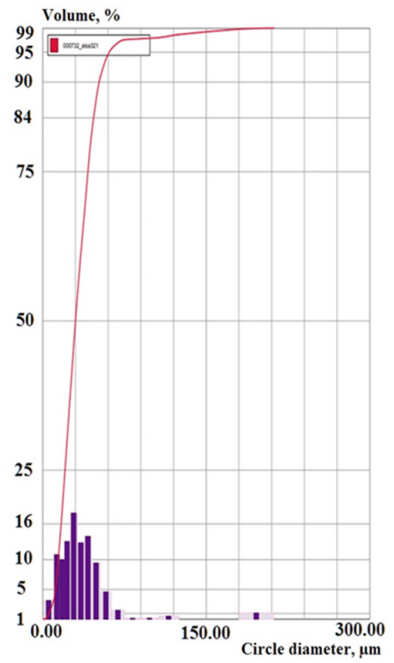

(b)

Figure 3. Morphology of powder particles PR12X18H10T: (a) magnification $\times 870$; (b) integral curve and differential histogram of powder particle size distribution. 
According to the obtained integral and differential histograms of the powder particle size distribution, it was concluded that the average particle size, $d_{a v}$ is $33.25 \mu \mathrm{m}$. The particle size in the range of $0-45 \mu \mathrm{m}$ is $82.35 \%$, which follows from the results of Table 2 . Thus, the analysis of PR-12X18H10T showed that the powder meets the requirements for powders for the LB-PBF.

Table 2. Powder particle size distribution.

\begin{tabular}{|c|c|c|c|c|c|c|c|c|c|c|c|c|c|c|c|c|}
\hline Size $(\mu \mathrm{m})$ & $\begin{array}{l}8 \\
8 \\
0 \\
1 \\
0 \\
0 \\
\text { ○. }\end{array}$ & $\stackrel{0}{1}$ & 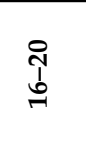 & 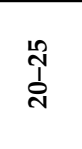 & 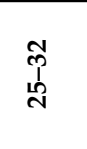 & $\begin{array}{c}\infty \\
\stackrel{\infty}{1} \\
1 \\
\text { N }\end{array}$ & $\begin{array}{l}n \\
\infty \\
\infty \\
\infty\end{array}$ & $\begin{array}{l}n \\
1 \\
1 \\
\text { ñ }\end{array}$ & $\begin{array}{l}n \\
0 \\
0 \\
n\end{array}$ & $\begin{array}{l}n \\
\hat{1} \\
3 \\
0\end{array}$ & $\begin{array}{l}\text { के } \\
\text { ñ }\end{array}$ & 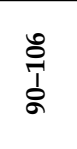 & 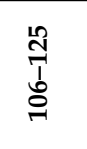 & 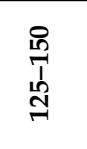 & $\begin{array}{l}\infty \\
\stackrel{\infty}{7} \\
0 \\
1 \\
\end{array}$ & 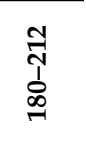 \\
\hline Volume \% & 3.2 & 10.93 & 10.1 & 13.18 & 17.97 & 12.93 & 14.04 & 9.52 & 4.63 & 1.54 & 0.17 & 0.18 & 0.54 & 0 & 0 & 1.08 \\
\hline Total volume \% & 3.2 & 14.12 & 24.23 & 37.41 & 55.38 & 68.31 & 82.35 & 91.87 & 96.5 & 98.05 & 98.21 & 99.4 & 98.94 & 98.94 & 98.94 & 100.01 \\
\hline
\end{tabular}

The modes for the manufacture of products from steel 12X18H10T by the LB-PBF were determined by using parametric analysis. Parametric analysis is based on varying process parameters. The main parameters affecting the quality of the manufactured specimens are the laser power, scanning speed, thickness of the powder layer and type of scanning strategy. The basic process mode for steel 12X18H10T is presented in Table 3.

Table 3. LB-PBF process mode for the manufacture of products from steel 12X18H10T.

\begin{tabular}{cc}
\hline Parameters & Value \\
\hline Laser power, $\mathrm{W}$ & 50 \\
\hline Laser mode & Continuous \\
\hline Laser beam diameter, $\mu \mathrm{m}$ & 100 \\
\hline Scanning speed, $\mathrm{mm} / \mathrm{s}$ & 80 \\
\hline Layer thickness, $\mu \mathrm{m}$ & 50 \\
\hline Scanning strategy & Two-zone \\
\hline Protective environment & Nitrogen \\
\hline
\end{tabular}

This mode for $12 \mathrm{X} 18 \mathrm{H} 10 \mathrm{~T}$ powder makes it possible to obtain dense products with a minimum number of pores. The percentage of pores on the plane of the cross-section is $0.06-0.08 \%$, which indicates a homogeneous material and complete penetration of the powder particles. Dual-zone scanning strategy allows us to produce products with a great isotropy of properties.

Comparative studies of the physical properties of the specimens made by the LB-PBF and conventionally manufactured ones of the same steel grade were carried out (Table 4).

Table 4. Physical properties of specimens made by the LB-PBF and comparison with the properties of conventionally manufactured specimen of the same steel.

\begin{tabular}{ccc}
\hline Property & LB-PBF Specimen & $\begin{array}{c}\text { Conventionally } \\
\text { Manufactured Specimen }\end{array}$ \\
\hline Porosity $\mathrm{A}_{\mathrm{f}}, \%$ & 0.07 & - \\
\hline Roughness $\mathrm{Ra}, \mu \mathrm{m}$ & $15-18$ & - \\
\hline Density $\rho, \mathrm{g} / \mathrm{cm}^{3}$ & 7.84 & 7.94 \\
\hline $\mathrm{CLTE} \alpha$ in the range from 20 to $600{ }^{\circ} \mathrm{C}, 1 /{ }^{\circ} \mathrm{C}$ & $18.54 \times 10^{-6}$ & $18.61 \times 10^{-6}$ \\
\hline
\end{tabular}

The density of the specimens and the CLTE after the LB-PBF are almost the same as the conventionally manufactured ones. The dilatometric analysis of steel $12 \mathrm{X} 18 \mathrm{H} 10 \mathrm{~T}$ specimens was carried out by using a differential dilatometer. Analysis of the obtained 
dilatograms was carried out in the temperature range from 20 to $600{ }^{\circ} \mathrm{C}$. It showed that the change in dimensions is within acceptable limits, which will ensure the stability of the dimensions of the tooling in the nitriding process. Temperature range of ion-plasma nitriding (first stage $-570{ }^{\circ} \mathrm{C} 36 \mathrm{~h}$; second stage $-540{ }^{\circ} \mathrm{C} 12 \mathrm{~h}$ ), which correlates with the results of previous studies [14].

To study the mechanical properties, the specimens were prepared according to the mode indicated in Table 3. Table 5 shows the comparative characteristics of the mechanical properties of specimens made by the LB-PBF and conventionally manufactured specimen of the same steel.

Table 5. Results of the mechanical properties study of the specimens made by the LB-PBF and comparison with the properties of conventionally manufactured specimen of the same steel.

\begin{tabular}{ccc}
\hline Property & LB-PBF Specimen & $\begin{array}{c}\text { Conventionally } \\
\text { Manufactured Specimen }\end{array}$ \\
\hline Vickers hardness, $\mathrm{HV}$ & 228 & 169 \\
\hline Tensile strength $\sigma_{\mathrm{B}}, \mathrm{MPa}$ & 656 & 517 \\
\hline Yield strength $\sigma_{\mathrm{T}}, \mathrm{MPa}$ & 570 & 235 \\
\hline Relative elongation $\delta, \%$ & 47 & 39 \\
\hline
\end{tabular}

The results of the study show that the hardness, tensile strength, yield strength and elongation are higher than those of a traditionally manufactured specimens, and these results are consistent with the data of Reference [28].

The phase composition and structure of specimens from steel 12X18H10T made by the LB-PBF method before and after the nitriding process were investigated (Figures 4-7).

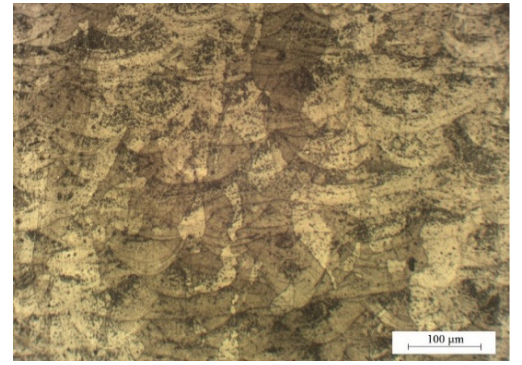

(a)

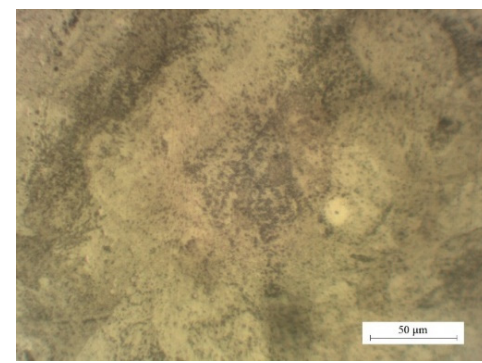

(b)

Figure 4. Microstructure of steel 12X18H10T manufactured by the LB-PBF: (a) cross-section perpendicular to the direction of laser scanning, $\times 200$; (b) longitudinal cross-section parallel to the direction of laser scanning, $\times 500$.

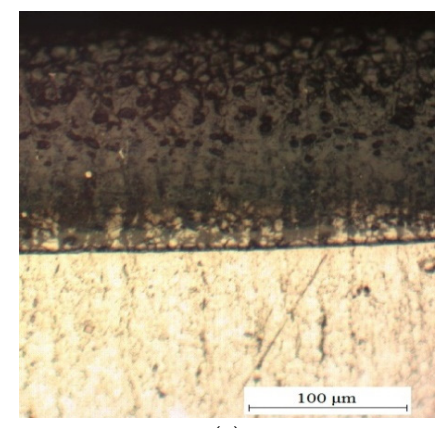

(a)

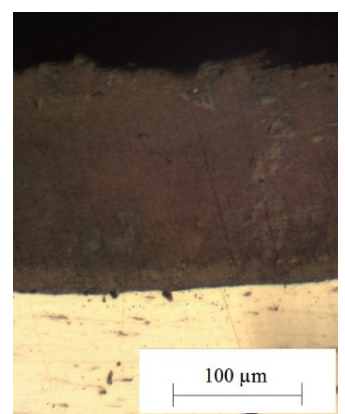

(b)

Figure 5. Microstructure of the nitrided layer on a specimen from steel 12X18H10T: (a) a specimen made by conventional method, layer depth $0.19 \mathrm{~mm}$, microhardness 1251 HV5; (b) LB-PBF specimen, dark field image, layer depth $0.16 \mathrm{~mm}$, microhardness $1352 \mathrm{HV} 5$. 


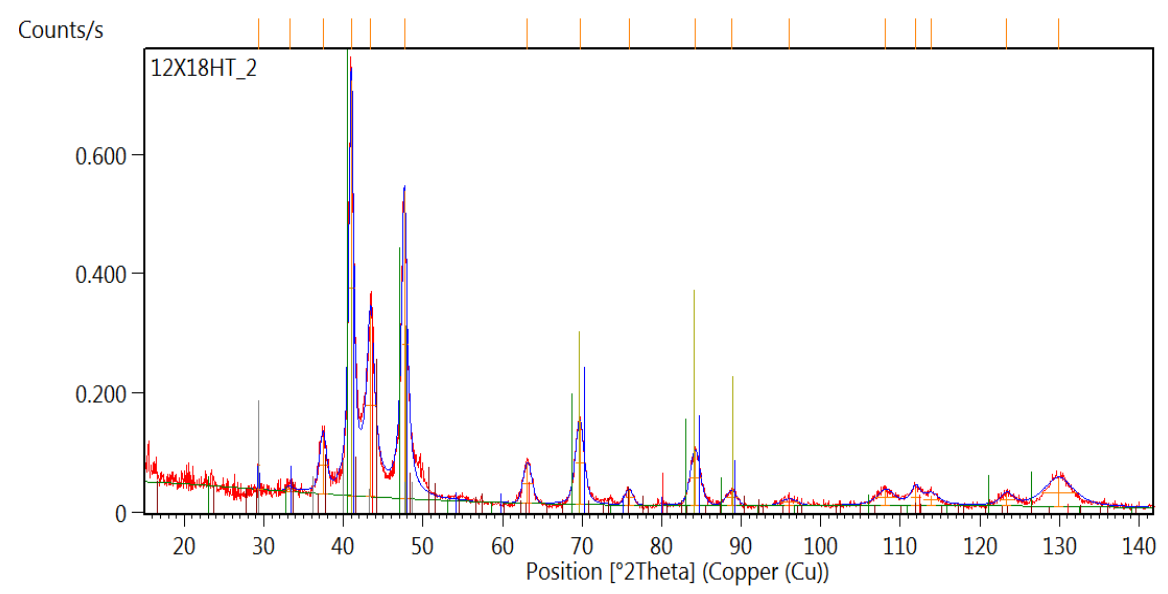

Figure 6. X-ray diffraction pattern of a nitrided layer on a 12X18H10T steel specimen manufactured by the LB-PBF.

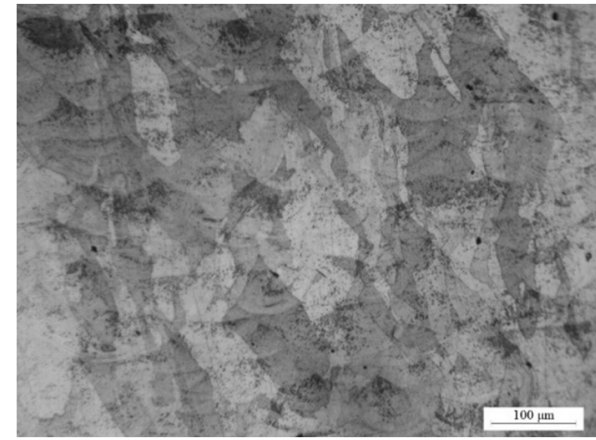

(a)

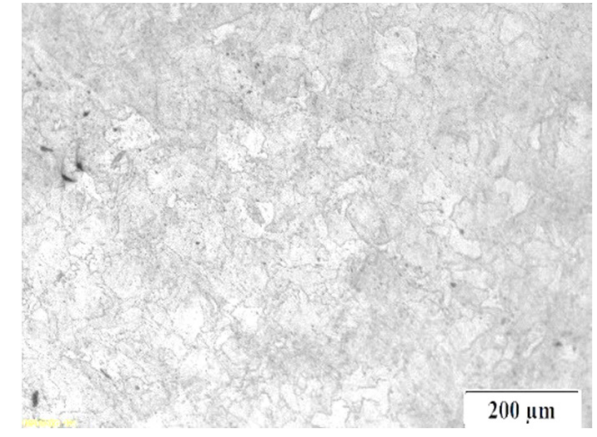

(b)

Figure 7. Microstructure of the core of a nitrided LB-PBF steel 12X18H10T specimen: (a) cross-section perpendicular to the direction of laser scanning and (b) longitudinal cross-section.

Figure 4 shows the microstructure of steel after the LB-PBF. The boundaries of the melt pools with an arcuate configuration are visible on the cross-section (Figure 4a). This is due to the Gaussian energy distribution of the laser beam. The direction of crystal growth in the central zone of the melt pool does not change significantly when crossing the boundary between the layers. There, epitaxial growth of the next layer on the previous one is possible.

Boundaries are observed both between the melt pools (oval configuration) and between the tracks in the longitudinal cross-section (Figure 4b). Accumulations of carbides are visible as a result of thermal cycling near the boundaries of the melt pools and at the boundaries between the tracks. After quenching from the liquid state, which occurs during the crystallization of the melt pool, tempering occurs at different temperatures while reheating. The tempering temperature depends on the distance from the heating source.

The structure of the steel before heat treatment (i.e., immediately after fabrication by the LB-PBF method) is $\gamma$-Fe and $\alpha$-Fe; the intermetallic compound $\mathrm{FeNi}$, iron carbide $\mathrm{Fe} 3 \mathrm{C}$ and $\mathrm{FeO}$ oxide are also formed in steel by the LB-PBF method.

Two-stage nitriding of steel (first stage $-570{ }^{\circ} \mathrm{C}$ for $36 \mathrm{~h}$; second stage $-540{ }^{\circ} \mathrm{C}$ for $12 \mathrm{~h}$ (nitriding mode for spheroidal graphite iron)) showed that the depth of the nitrided layer on the specimen made by the LB-PBF method is less than on the specimens obtained by the conventional method (Figure 5). That is explained by the more dispersed structure of steel after the LB-PBF.

The phase analysis of the nitrided layer on 12X18H10T steel LB-PBF specimens and conventionally manufactured specimens shows that, in both cases, a nitride zone is formed, which is a single-phase region of the $\gamma^{\prime}$-phase of $\mathrm{Fe}_{4} \mathrm{~N}, \gamma$-solid solution of nitrogen in austenite and chromium nitrides $\mathrm{CrN}$ (Figure 6). 
Our analysis of the microstructure of the core of a nitrided LB-PBF specimen from $12 \mathrm{X} 18 \mathrm{H} 10 \mathrm{~T}$ steel (Figure 7) showed that annealing that occurs during nitriding leads to the blurring of the boundaries of the melt pools and the formation of a structure characteristic of austenitic steels-polyhedral grains.

Thus, studies of the microstructure of specimens made from 12X18H10T steel and subjected to nitriding will not lead to the embrittlement of the layer on the tooling made by the LB-PBF. The structure of the core improves, as a result of annealing at $580^{\circ} \mathrm{C}$, the texture, leading to decreases in the anisotropy of properties and residual stresses. The obtained results show that the selected mode of ion-plasma nitriding (first stage $-570{ }^{\circ} \mathrm{C}$ for $36 \mathrm{~h}$; second stage $-540^{\circ} \mathrm{C}$ for $12 \mathrm{~h}$ ) will not lead to the deterioration of the characteristics of the selected steel.

The kinetics of the depth growth of nitrided layers and the change in hardness on steel 12X18H10T were studied.

The diffusion of nitrogen into steel is extremely difficult, due to the predominant amount of the $\gamma$-phase and the dense chromium oxide film. However, this steel is nitrided by the ion-plasma method, due to cathodic sputtering in hydrogen or argon, in order to remove the oxide film, and the so-called "bombardment" of nitrogen atoms into the steel, due to which the diffusion process proceeds faster. For the experiments, we used specimens made by the LB-PBF and the conventional process. The specimens were subjected to fivefold nitriding in a two-stage mode: first stage $-570{ }^{\circ} \mathrm{C}$ for $36 \mathrm{~h}$; second stage $-540{ }^{\circ} \mathrm{C}$ for $12 \mathrm{~h}$ (nitriding mode for spheroidal graphite iron). The results of the dependence of the depth of the nitrided layer on time are shown in Figure 8a, the hardness in Figure 8b, (blue line-depth of the layer on the conventionally manufactured specimens, red line-for the specimens made by the LB-PBF).

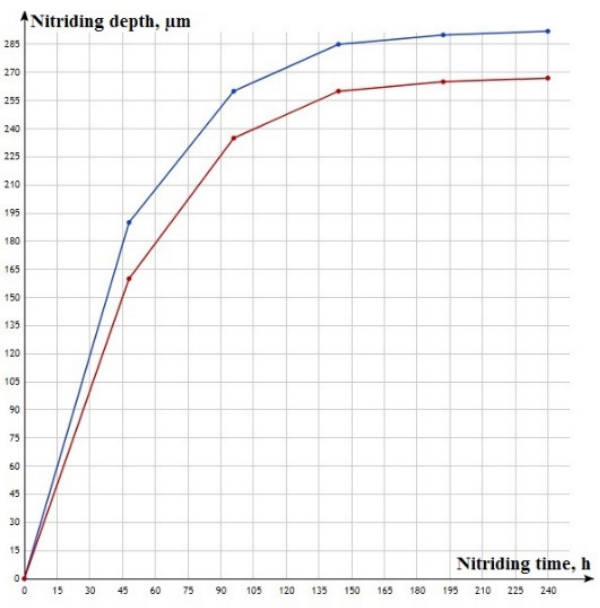

(a)

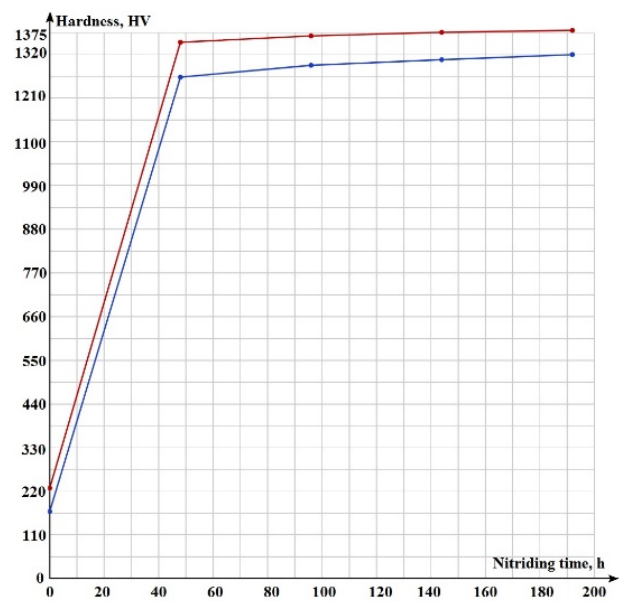

(b)

Figure 8. Dependence of the depth and hardness of the nitrided layer on the nitriding time. Blue line $=$ conventionally manufactured specimens. Red line $=$ specimens made by the LB-PBF. (a) Layer depth and (b) layer hardness.

Nitrogen diffusion, in both cases, proceeds in accordance with Fick's first law: $J=-D \frac{\partial C}{\partial x}$, where $J$ is the diffusion flux, $D$ is the diffusion coefficient and $\frac{\partial C}{\partial x}$ is the concentration gradient. There is a sharp increase in depth in $144 \mathrm{~h}$ to $0.26 \mathrm{~mm}$ on the plot of the nitrided layer depth dependence on time, and then the process slows down and goes to a depth of no more than $0.27 \mathrm{~mm}$.

For the LB-PBF specimen, the diffusion of nitrogen into the depth of the metal is noticeably slower. The hardness of the layer is insignificantly higher than for the conventionally manufactured specimen. It is probably caused by the finer structure of the LB-PBF specimen. 
According to the selected modes (Table 3), and in accordance with the developed model (Figure 2), the equipment was made from 12X18H10T steel by the LB-PBF. The benefit of the modified tooling is to reduce the number of elements (from 13 to 4 ). In addition, it serves to improve the quality of the nitrided layer on the working surface of the block part made from spheroidal graphite iron. The tooling consists of a monolithic casing with thin-walled bushings, and two thin-walled covers covering the small outer and central inner diameters (Figure 9).

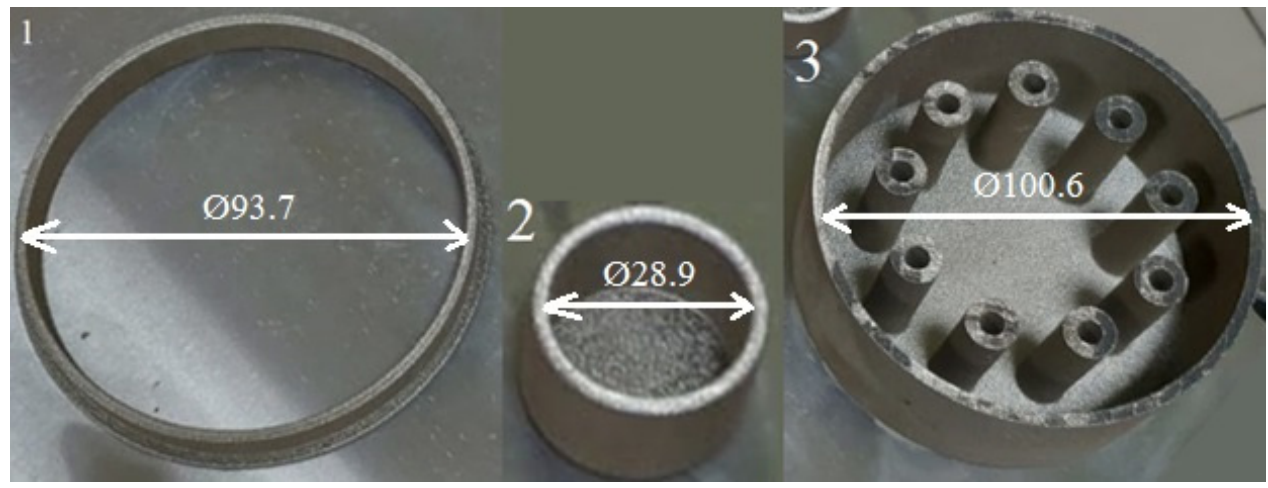

Figure 9. Tooling: 1—external cover, 2-inner cover and 3-casing.

An improvement in the quality of the nitrided layer is ensured by replacing the balls covering the non-nitrided holes with thin-walled bushings (Figure 9). Non-nitrided holes are closed from below, thereby eliminating the effect of shielding the spheroidal graphite iron surface by balls during the process of ion-plasma nitriding (Figure 10). As a result of shielding, a zone of local overheating appears, leading to a structural defect. The defect is the appearance of a zone of nitrogenous ferrite on the surface of the layer, which has a low hardness of 397-454 HV (Figure 10a). Comparative studies of the elemental composition in the surface zones of the defective layer (Figure 10) and in a similar area of the non-defective layer corresponding to the requirements of the technological process (Figure 11) by the method of energy dispersive spectroscopy (EDS) showed a decrease in the concentration of nitrogen and carbon in the defective layer.

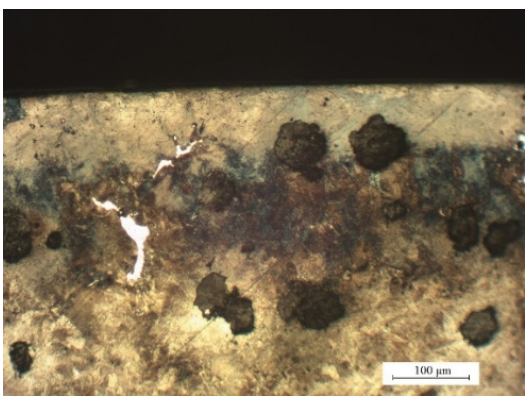

(a)

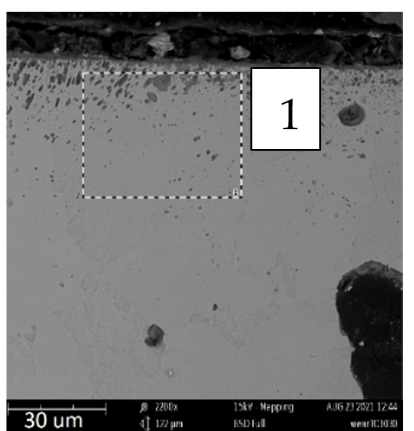

(b)

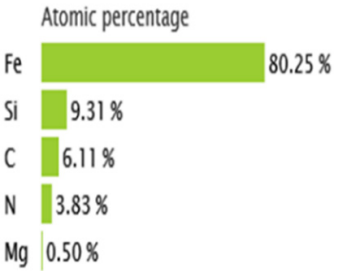

(c)

Figure 10. Nitrided layer of spheroidal graphite iron, layer defect: (a) microstructure of the zone with reduced hardness and depth (hardness 397-454 HV5, depth $0.23 \mathrm{~mm}$ ); (b) SEM image, measured area (1); (c) histogram of the elemental composition of area 1.

The use of modified tooling made by the LB-PBF from austenitic corrosion-resistant steel 12X18H10T (analogue of AISI 321) allows us to obtain a high-quality nitrided layer on the surface of the block part made from spheroidal graphite iron. 


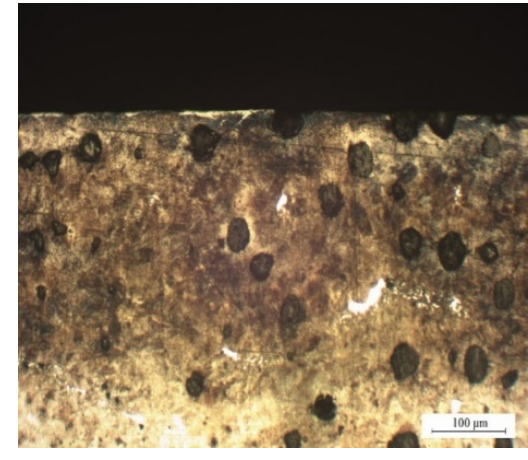

(a)

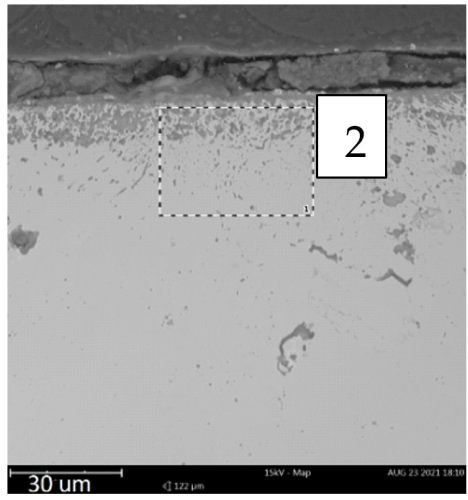

(b)

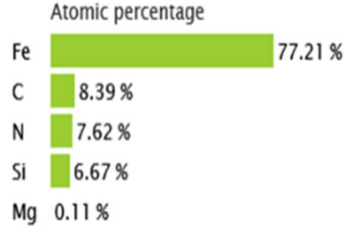

(c)

Figure 11. Nitrided layer of spheroidal graphite iron that meets the requirements of the technological process: (a) layer microstructure, hardness 552-603 HV5, depth $0.31 \mathrm{~mm}$; (b) SEM image, measured area (2); (c) histogram of the elemental composition of area 2.

\section{Conclusions}

A technological process for the modified tooling manufacturing by the LB-PBF from 12X18H10T steel powder (analogue of AISI 321) was developed. Modified tooling protects certain surfaces of the part that are not subject to nitriding. That allows us to obtain a uniform high-quality nitrided layer on the working surface of the part made from spheroidal graphite iron. The proposed technology provides the required performance characteristics of the tooling.

Research confirms the fact that steel has good dimensional stability. The temperature coefficient of linear expansion of steel after the LB-PBF is within acceptable limits $\left(18.6 \times 10^{-6} 1 /{ }^{\circ} \mathrm{C}\right)$. Phase-transition $\gamma \leftrightarrow \alpha$ does not occur in the temperature range $500-600{ }^{\circ} \mathrm{C}$ (nitriding temperature range). Tooling made from austenitic steel withstands long-term operation and multiple usage. That is shown by studies of the kinetics of the nitrided layers' depth growth and the change in hardness on steel 12X18H10T in the process of ion-plasma nitriding. The results of the studies show that protective tooling made from steel $12 \mathrm{X} 18 \mathrm{H} 10 \mathrm{~T}$ can be used industrially for the surfaces of spheroidal graphite iron blocks used in piston pumps of aircraft engines in order to improve the quality of the nitrided layer.

Author Contributions: Conceptualization, A.M. and S.G.; data curation, A.M. and S.G.; formal analysis, T.T. and S.E.; funding acquisition, A.M. and S.G.; investigation, E.G. and R.K.; methodology, T.T.; project administration, S.G.; resources, R.K. and S.G.; software, E.G. and S.E.; supervision, A.M. and S.G.; validation, T.T. and R.K.; visualization, A.M. and E.G.; writing-original draft, T.T., E.G. and S.E.; writing - review and editing, T.T. and S.E. All authors have read and agreed to the published version of the manuscript.

Funding: The study was supported by a grant of the Russian Science Foundation (project No. 20-19-00620).

Institutional Review Board Statement: Not applicable.

Informed Consent Statement: Not applicable.

Data Availability Statement: Not applicable.

Acknowledgments: The authors carried out research on the equipment of the Center of collective use of MSUT "STANKIN" (agreement No. 075-15-2021-695).

Conflicts of Interest: The authors declare no conflict of interest. 


\section{References}

1. ASTM 1. Standard Terminology for Additive Manufacturing Technologies: ASTMF2792-12a; ASTM International: West Conshohocken, PA, USA, 2012.

2. ISO/ASTM. 52900:2015 Additive Manufacturing_General Principles_Terminology; ISO/ASTM International: Geneva, Switzerland, 2015; p. 19. Available online: https:/ /www.sis.se/api/document/preview/919975/ (accessed on 15 August 2015).

3. Grigor'Ev, S.N.; Tarasova, T.V. Possibilities of the Technology of Additive Production for Making Complex-Shape Parts and Depositing Functional Coatings from Metallic Powders. Met. Sci. Heat Treat. 2016, 57, 579-584. [CrossRef]

4. Hemmati, I.; Ocelík, V.; De Hosson, J.T.M. Microstructural characterization of AISI 431 martensitic stainless steel laser-deposited coatings. J. Mater. Sci. 2011, 46, 3405-3414. [CrossRef]

5. Zhang, C.; Zhu, J.; Ji, C.; Guo, Y.; Fang, R.; Mei, S.; Liu, S. Laser powder bed fusion of high-entropy alloy particle-reinforced stainless steel with enhanced strength, ductility, and corrosion resistance. Mater. Des. 2021, 209, 109950. [CrossRef]

6. Khmyrov, R.S.; Grigoriev, S.N.; Okunkova, A.A.; Gusarov, A.V. On the Possibility of Selective Laser Melting of Quartz Glass. Phys. Procedia 2014, 56, 345-356. [CrossRef]

7. Otto, M.; Pilz, S.; Gebert, A.; Kühn, U.; Hufenbach, J. Effect of Build Orientation on the Microstructure, Mechanical and Corrosion Properties of a Biodegradable High Manganese Steel Processed by Laser Powder Bed Fusion. Metals 2021, 11, 944. [CrossRef]

8. Wang, Y.; Xiong, W.; Tang, D.; Hao, L.; Li, Z.; Li, Y.; Cheng, K. Rheology effect and enhanced thermal conductivity of diamond/metakaolin geopolymer fabricated by direct ink writing. Rapid Prototyp. J. 2021, 27, 837-850. [CrossRef]

9. Karimi, M.S.; Yeganeh, M.; Zaree, S.A.; Eskandari, M. Corrosion behavior of 316L stainless steel manufactured by laser powder bed fusion (L-PBF) in an alkaline solution. Opt. Laser Technol. 2021, 138, 106918. [CrossRef]

10. Yadroitsev, I.; Bertrand, P.; Antonenkova, G.; Grigoriev, S.; Smurov, I. Use of track/layer morphology to develop functional parts by selective laser melting. J. Laser Appl. 2013, 25, 052003. [CrossRef]

11. Smurov, I.; Doubenskaia, M.; Grigoriev, S.; Nazarov, A. Optical Monitoring in Laser Cladding of Ti6Al4V. J. Therm. Spray Technol. 2012, 21, 1357-1362. [CrossRef]

12. Doubenskaia, M.; Pavlov, M.; Grigoriev, S.; Tikhonova, E.; Smurov, I. Comprehensive Optical Monitoring of Selective Laser Melting. J. Laser Micro Nanoeng. 2012, 7, 236-243. [CrossRef]

13. Gusarov, A.; Grigoriev, S.N.; Volosova, M.A.; Melnik, Y.A.; Laskin, A.; Kotoban, D.V.; Okunkova, A.A. On productivity of laser additive manufacturing. J. Mater. Process. Technol. 2018, 261, 213-232. [CrossRef]

14. Facchini, L.; Vicente, N.; Lonardelli, I.; Magalini, E.; Robotti, P.; Molinari, A. Metastable Austenite in 17-4 Precipitation-Hardening Stainless Steel Produced by Selective Laser Melting. Adv. Eng. Mater. 2010, 12, 184-188. [CrossRef]

15. Gladush, G.G.; Smurov, I. Physics of Laser Materials Processing: Theory and Experiment; Springer Science \& Business Media: Berlin, Germany, 2011; 534p.

16. Shishkovsky, I.V. Laser Synthesis of Functional Mesostructures and Tridimensional Products; FIZMATLIT: Moscow, Russia, 2009; 424p.

17. Tarasova, T.V.; Gusarov, A.V.; Protasov, K.E.; Filatova, A.A. The influence of thermal fields on the structure of corrosion-resistant steels in various laser processing schemes. Metall. Heat Treat. Met. 2017, 59, 37-44.

18. Nowotny, S.; Tarasova, T.V.; Filatova, A.A.; Dolzhikova, E.Y. Methods for Characterizing Properties of Corrosion-Resistant Steel Powders Used for Powder Bed Fusion Processes. In Materials Science Forum; Trans Tech Publications: Zurich, Switzerland, 2016; Volume 876, pp. 1-7.

19. Badrossamay, M.; Childs, T. Further studies in selective laser melting of stainless and tool steel powders. Int. J. Mach. Tools Manuf. 2007, 47, 779-784. [CrossRef]

20. Abd-Elghany, K.; Bourell, D. Property evaluation of 304L stainless steel fabricated by selective laser melting. Rapid Prototyp. J. 2012, 18, 420-428. [CrossRef]

21. Kameneva, A.L.; Minkova, A.A.; Cherkashneva, N.N.; Karmanov, V.V. Correlation between heat treatment process parameters, phase composition, texture, and mechanical properties of $12 \mathrm{H} 18 \mathrm{~N} 10 \mathrm{~T}$ stainless steel processed by selective laser melting. In IOP Conference Series: Materials Science and Engineering; IOP Publishing: Bristol, UK, 2018; Volume 447.

22. Grigoriev, S.N.; Metel, A.S.; Tarasova, T.V.; Filatova, A.A.; Sundukov, S.K.; Volosova, M.A.; Okunkova, A.A.; Melnik, Y.A.; Podrabinnik, P.A. Effect of Cavitation Erosion Wear, Vibration Tumbling, and Heat Treatment on Additively Manufactured Surface Quality and Properties. Metals 2020, 10, 1540. [CrossRef]

23. Metel, A.S.; Grigoriev, S.N.; Tarasova, T.V.; Filatova, A.A.; Sundukov, S.K.; Volosova, M.A.; Okunkova, A.A.; Melnik, Y.A.; Podrabinnik, P.A. Influence of Postprocessing on Wear Resistance of Aerospace Steel Parts Produced by Laser Powder Bed Fusion. Technologies 2020, 8, 73. [CrossRef]

24. Roehling, T.T.; Wu, S.S.; Khairallah, S.A.; Roehling, J.D.; Soezeri, S.S.; Crumb, M.F.; Matthews, M.J. Modulating laser intensity profile ellipticity for microstructural control during metal additive manufacturing. Acta Mater. 2017, 128, 197-206. [CrossRef]

25. Sova, A.; Grigoriev, S.; Okunkova, A.; Smurov, I. Potential of cold gas dynamic spray as additive manufacturing technology. Int. J. Adv. Manuf. Technol. 2013, 69, 2269-2278. [CrossRef]

26. Sova, A.; Grigoriev, S.; Okunkova, A.; Smurov, I. Cold spray deposition of 316L stainless steel coatings on aluminium surface with following laser post-treatment. Surf. Coat. Technol. 2013, 235, 283-289. [CrossRef] 
27. Sova, A.; Okunkova, A.; Grigoriev, S.; Smurov, I. Velocity of the Particles Accelerated by a Cold Spray Micronozzle: Experimental Measurements and Numerical Simulation. J. Therm. Spray Technol. 2013, 22, 75-80. [CrossRef]

28. Wang, Z.; Palmer, T.A.; Beese, A.M. Effect of processing parameters on microstructure and tensile properties of austenitic stainless steel 304L made by directed energy deposition additive manufacturing. Acta Mater. 2016, 110, 226-235. [CrossRef] 